\title{
A interdisciplinaridade como instrumento de ação comunicativa $^{1}$
}

\author{
Marco Donizete Paulino da Silva \\ Doutorando; Universidade Federal de São Carlos, São Carlos, SP, Brasil; \\ marco_donizete@yahoo.com.br \\ Luciana de Souza Gracioso \\ Doutora; Universidade Federal de São Carlos, São Carlos, SP, Brasil; \\ lugracioso@yahoo.com.br
}

\begin{abstract}
Resumo: Parte-se da percepção da necessidade de uma consideração holística dos elementos epistemológicos envolvidos na construção do conhecimento no tempo contemporâneo, tendo como elementos-chave, tanto a exigência de uma conscientização cidadã do indivíduo quanto o uso de um instrumento que potencialize essa conscientização, ainda que se reconheça o caráter utópico desse projeto. O conceito de interdisciplinaridade (e seus múltiplos sentidos) foi entendido como recurso de aplicação recorrente no desenvolvimento e ampliação do conhecimento humano e científico. Da articulação dessas premissas, propôs-se a consideração do termo interdisciplinaridade como um instrumento-tecnologia de ação comunicativa, capaz de intermediar o mundo da vida e os sistemas sócio-institucionais, promovendo o encontro (ou resultando do encontro) de intersubjetividades de sujeitos atuantes nesses dois espaços. Objetivando-se verificar a pertinência dessa proposição, aplicou-se a análise hermenêuticodialética sobre textos nacionais e internacionais que abordam o conceito de interdisciplinaridade na perspectiva de vários teóricos do campo da Filosofia e da Sociologia. As argumentações em torno desse tema se deram por meio dos seguintes conceitos-base, nas seguintes filiações: Ação Comunicativa, Racionalidade, e Pretensões de Validez, por Jürgen Habermas; e, de Interdisciplinaridade, em Leo Apostel et al. - com considerações de Japiassu e Alvarenga et al. Concluiu-se que o ambiente da esfera pública é, potencialmente, um espaço de construção interdisciplinar do conhecimento e que sua natureza conscientizadora poderia beneficiar a promoção mais abrangente da interdisciplinaridade em espaços diferenciados.
\end{abstract}

Palavras-chave: Interdisciplinaridade. Teoria da Ação Comunicativa. Método hermenêuticodialético. Sujeito da Ação Comunicativa. Mundo da Vida.

\section{Introdução}

Pensar a sociedade como um elemento determinante de um processo epistemológico mais 


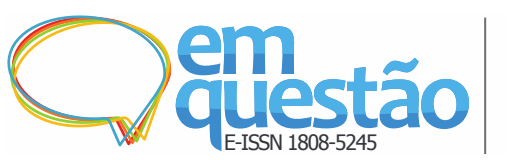

amplificado é, a nosso ver, estender a essa sociedade a responsabilidade pelas ocorrências em seu tecido, tendo nos processos políticos um forte elemento decisório. Nesse sentido, um conceito que nos parece coerente à proposição de um Sujeito como um agente social responsável (seja ele um sujeito profissional ou apenas um indivíduo incluso no sistema social contemporâneo) é o de Esfera Pública (ou Arena Pública) de Habermas (1984), conceito pelo qual as decisões de interesse público (que atingem uma totalidade de indivíduos em uma dada sociedade) são debatidas em situação de igualdade de condições decisórias (com capacidade de análise dos fatos e de acesso aos instrumentos de comunicação desses fatos) pelos sujeitos em plena ação comunicativa.

Em nossa acepção, o desenvolvimento de um compromisso responsável entre os indivíduos pertencentes a uma dada sociedade - em um projeto epistemológico racional e holisticamente mais satisfatório tanto para a manutenção da vida terrestre quanto para o melhoramento dos laços humanos - será uma realidade quando os conhecimentos forem comunitariamente compartilhados de maneira interdisciplinar, ou seja, quando o resultante desses compartilhamentos promova uma mudança razoável na "axiomática" cidadã, sobretudo por se basear em um processo argumentativo crítico, capaz de identificar impactos negativos e/ou catastróficos, resultantes de decisões que nem sempre priorizam o bem estar dos seres e o bom estado dos objetos naturais no âmbito sócio-planetário.

Não queremos dizer com isso que nossa crítica não está isenta de fragilidades, uma vez que a conciliação entre pensamentos e realidades díspares - em um contexto cultural complexo, de grande fragmentação, no sentido outorgado por Aragão (1992) à visão habermesiana da Modernidade - também deve ser colocada em pauta, sobretudo porque reconhecemos que tal proposta carrega em si um forte caráter idealista - como salientado por Raslan Filho (2012) -, de difícil conciliação com a realidade em que vivemos, favorecendo uma noção utópica ao empreendimento.

No entanto, a partir dessa constatação e reconhecimento, lançamos como nossa defesa a proposição de Santos (2001), em se construir uma ideia de Utopia que, como objetivo a ser buscado e nunca alcançado - uma vez que o projeto utópico está sempre além de sua realidade, no futuro -, exija sempre aperfeiçoamentos na realidade presente, visando adequação ao projeto.

Alguns conceitos retirados de Habermas (1987) foram considerados elementares de nossa abordagem do tema da interdisciplinaridade como instrumento de mediação 
entre uma realidade temporal e historicamente localizada - nosso mundo da vida contemporâneo - e os espaços institucionais e sociais - mundo dos sistemas. Nesse sentido, tanto os Sujeitos Agentes quanto os Espaços Sociais de ação desses sujeitos são elementos interdependentes de uma Esfera Pública - ou Arena Pública - de debate em que os argumentos e pretensões de validez das proposições feitas nesse processo de avaliação decisória sobre as intervenções humanas num âmbito global.

Como recorte, utilizaremos a Ciência como um sistema institucional contraposto ao mundo da vida. Nesse sentido, justificamos nossa escolha pela consideração de González de Gómez (2011, p. 235) de que uma nova universidade, como espaço de construção do pensamento científico numa nova ordem sócio-cultural: “[...] é interpelada por demandas e proposições que visam a definir as sociedades por sua imersão em novos modos de produção da informação e do conhecimento.”, sendo responsável, então:

[...] por oferecer sua interpretação das necessidades culturais contemporâneas, em seus contextos de intervenção, atendendo aos desafios da pluralidade cultural e epistemológica dos conhecimentos, assumindo suas plurais funções e priorizando as metas inclusivas do projeto democrático. (GONZÁLEZ DE GÓMEZ, 2011, p. 235).

Convém observarmos que, ainda que em nossa perspectiva a teoria habermesiana seja considerada a mais adequada para construção epistemológica em um nível social abrangente A Epistemologia Geral de Blanché (1978) e Japiassu (1992) -, também concordamos não ser a única ${ }^{2}$.

Finalmente, cabe enunciar que além dos termos acima mencionados (considerados inerentes à nossa proposição investigativa de entender a interdisciplinaridade como instrumento-tecnologia de intermediação entre mundo da vida e sistemas sócio-institucionais), outros conceitos-chave pelos quais orientamos nossa análise foram os conceitos de: Ação Comunicativa, Racionalidade, e Pretensões de Validez, de Jurgen Habermas (1987); e de Interdisciplinaridade, em Leo Apostel et al. (1972) - com considerações de Japiassu (1976) e Alvarenga et al. (2011).

\section{Método hermenêutico-dialético e corpus analítico}

Consideramos a pesquisa como de ordem documental, observando a caracterização expressa em Gil (1989), segundo a qual, esse tipo de pesquisa se vale: "[...] de materiais que 
não receberam ainda trabalho analítico, ou que ainda podem ser reelaborados de acordo com os objetivos da pesquisa." (p. 73). Tais objetivos, ainda com base em Gil (1989), orientaramse por uma perspectiva dialética, contrária: “[...] a todo conhecimento rígido. Tudo é visto em constante mudança: sempre há algo que nasce e se desenvolve e algo que se desagrega e se transforma." (p. 32).

Por essa consideração, optou-se por uma abordagem de análise discursiva pelo método de Análise Hermenêutico-dialética que, segundo as prescrições de Minayo (2002) se propõem, sinteticamente: delimitação hermenêutica do interpretante e do interpretado, com suas respectivas condições de análise (pesquisador) e produção (autor teórico); e, contraposição dialética dos resultantes dessa aplicação hermenêutica.

O corpus foi composto por textos pertencentes a duas obras:

a) Leo Apostel et al. (1972) - publicação resultante do I Seminário internacional sobre pluri e interdisciplinaridade, ocorrido na Universidade de Nice (França), em 7-12 de setembro de 1970;

b) Jürgen Habermas (1987) - obra que expõe, detalhadamente, a proposição do filósofo alemão acerca de uma Teoria de Ação Comunicativa, postulando condições dialógicocomunicacionais abrangentes no nível societário global e territorial.

Complementarmente aos textos selecionados de Apostel et al. (1972) - pertencentes a Heckhausen (1972) e Jantsch (1972) -, utilizamos tanto as considerações de Japiassu (1976) quanto as de Alvarenga et al (2011). Da mesma maneira, em relação ao texto selecionado de Habermas (1987), utilizamos as considerações de Aragão (1992). Tais articulações foram entendidas como elaborações pertinentes de menção em nossa proposta de abordagem dos temas de Interdisciplinaridade e de Ação Comunicativa. Observamos, ainda, que todos os textos abordam questões teóricas complexas e foram, conforme orientação metodológica, considerados como base teórica subjacente a premissa por nós sugerida: de possibilidade da Interdisciplinaridade funcionar como tecnologia de mediação intersubjetiva entre componentes pertences ao Mundo dos Sistemas e ao Mundo da Vida (conceitos abordados numa das seções subsequentes). 


\section{Recortes teóricos sobre interdisciplinaridade}

Segundo Alvarenga et al. (2011), os textos apresentados em Apostel et al. (1972) são bases clássicas pelas quais a maioria das discussões sobre o conceito de Interdisciplinaridade orientaram-se até a primeira década do ano 2000. Em nosso recorte, no entanto, restringimos nossa abordagem aos dois teóricos mencionados na seção anterior - Heckhausen e Jantsch pela limitação do espaço de articulação aqui estabelecido, assim como, pelo uso complementar de uma segunda obra, a de Japiassu (1976), filósofo que aborda os mesmos teóricos, fazendo observações de interesse a nossa proposição: aspecto integrativo como elemento característico do processo interdisciplinar.

Começando por Heckhausen (1972), ele propõe especificar o sentido do termo Interdisciplinaridade pela consideração prévia do termo Disciplina, abordando este último como conceito epistemológico - diferenciando-o das divisões tradicionais (departamentos universitários) conferidas ao mesmo até então. Na proposição do autor, à caracterização disciplinar se propõe, complementarmente, uma sucessiva divisão de tipos interdisciplinares, considerando, no entanto, que tal procedimento aplicar-se-ia somente em disciplinas empíricas - apoiadas na observação e não na dedução pura.

Segundo Alvarenga et al. (2011), à essa divisão didática de classificação da ciência propõem-se sete critérios de definição do conceito de Disciplina: (1) existência de objeto próprio; (2) campo de conhecimento definido; (3) nível de integração teórica; (4) métodos próprios de investigação; (5) instrumentos epistemológicos de análise; (6) aplicação prática; e, (7) dinâmica de suas contingências históricas.

Segundo Heckhausen (1972, p. 86, tradução nossa), a consideração desses critérios:

[...] leva à diferenciação de pelo menos seis tipos de interdisciplinaridade. Ao mesmo tempo, esta tipologia aponta vários impulsos para a interdisciplinaridade no campo da pesquisa, no campo da prática vocacional e na complexa interação entre estes dois campos.

Tais Interdisciplinaridades são traduzidas/denominadas em Alvarenga et al. (2011) como de seguintes tipos: heterogênea; pseudo-interdisciplinaridade (falsa); auxiliar; composta; complementar e unificadora. Tais tipos, no entanto, são reorganizados por Alvarenga et al. (2011) conforme os campos de aplicação do conceito, resultando suas categorizações em Campos de interesse, nas condições apresentadas pelo Quadro 1: 
Quadro 1 - Distribuição dos tipos de Interdisciplinaridade apresentados por Heckhausen (1972) e categorizados por Alvarenga et al. (2011) em campos de interesse de aplicação

\begin{tabular}{|c|c|c|}
\hline Campo & Tipo & Característica \\
\hline Ensino & Heterogênea & $\begin{array}{c}\text { Diminui esforços de compreensão entre elementos } \\
\text { disciplinares distintos, tentando contrabalançar efeitos } \\
\text { de especialização. }\end{array}$ \\
\hline Profissional & Composta & $\begin{array}{l}\text { Representa aptidão técnica em "contextualizar" } \\
\text { problemas complexos sociais, considerando-os objeto } \\
\text { comum a várias disciplinas. }\end{array}$ \\
\hline \multirow[t]{2}{*}{ Científico } & Falsa & $\begin{array}{c}\text { Falsa concepção interdisciplinar resultante da simples } \\
\text { reunião de disciplinas que empregam os mesmos } \\
\text { instrumentos de análise. }\end{array}$ \\
\hline & Auxiliar & $\begin{array}{c}\text { Promove troca ou empréstimos de métodos ou técnicas } \\
\text { de pesquisa entre disciplinas, ocasionais ou não } \\
\text { ocasionais. }\end{array}$ \\
\hline \multirow[t]{2}{*}{ Pesquisa } & Complementar & $\begin{array}{l}\text { Surgida em regiões disciplinares fronteiriças imbricadas } \\
\text { (parcial ou integralmente) por convergência de vários } \\
\text { campos de estudos em nível correspondente (integração } \\
\text { teórica), mas, nem sempre coerente nos níveis teórico- } \\
\text { metodológios. }\end{array}$ \\
\hline & Unificadora & $\begin{array}{l}\text { Nível de convergência que atende ao critério de } \\
\text { coerência teórica e metodológica, promovendo uma } \\
\text { integração mais abrangente e profunda. }\end{array}$ \\
\hline
\end{tabular}

Fonte: Baseado em Alvarenga et al. (2011).

Jantsch (1972), em paráfrase de Alvarenga et al. (2011), reflete sobre relações entre ciência, ensino e inovação, defendendo como finalidade do ensino a promoção da inovação social (renovação de si mesma enquanto sociedade), considerando a Interdisciplinaridade e a Transdisciplinaridade como formas essenciais de ação inovativa. Nesse sentido, Jantsch (1972, p. 103, tradução nossa) observa que a Disciplinaridade na Ciência: “[...] é essencialmente um princípio estático que fica sem sentido se considerado no quadro de um sistema proposital." ${ }^{\text {, }}$ complementando:

Não é de admirar que, no momento em que a ciência é cada vez mais entendida como base, ou mesmo como aspecto integral, da ação humana criativa, a 
ênfase é mudada para abordagens mais ou menos interdisciplinares. ${ }^{5}$ (JANTSCH, 1972, p. 103, tradução nossa).

$\mathrm{O}$ autor apresenta sua ideia geral de Interdisciplinaridade pela acepção de que a mesma seria resultante de um processo em que:

\begin{abstract}
Uma axiomática comum para um grupo de disciplinas relacionadas é definida no próximo nível ou sub-nível hierárquico superior, introduzindo assim um senso de propósito; a interdisciplinaridade teleológica atua entre os níveis empírico e pragmático, a interdisciplinaridade normativa entre os níveis pragmáticos e normativos, a interdisciplinaridade intencional entre os níveis normativo e proposital. $^{6}$ (JANTSCH, 1972, p. 106, tradução nossa).
\end{abstract}

No que concerne aos tipos e "espaços" de aplicação da Interdisciplinaridade, Jantsch (1972) considera as formas de ocorrência Interdisciplinar em relação ao Sistema de Educação/Inovação (Education/Innovation System) que delibera várias modalidades/possibilidades relacionais, dentre as quais: as de Disciplinaridade Cruzada, Multi, Pluri, Trans, e Interdisciplinaridade.

O Quadro 2 apresenta tais tipos de relações interdisciplinares (representadas pelos seus prefixos), excetuando, especificamente, a Interdisciplinaridade, apresentada no quadro subsequente.

Quadro 2 - Apresentação sistemática das relações interdisciplinares de Jantsch (1972), com explicitação de suas potencialidades relacionais

\begin{tabular}{|c|c|c|c|c|}
\hline \multirow{2}{*}{ Caráter } & \multicolumn{2}{|c|}{ Tipo de Sistema } & Característica & Resultante \\
\cline { 2 - 3 } & Nível & Objetivos & & Nenhuma cooperação \\
\hline Multi & Único & Múltiplos & $\begin{array}{c}\text { Aparentemente não } \\
\text { relacional }\end{array}$ & Eestaque de relações \\
\hline Pluri & Único & Múltiplos & $\begin{array}{c}\text { Agrupamento em mesmo } \\
\text { nível hierárquico }\end{array}$ & $\begin{array}{c}\text { Com cooperação } \\
\text { Sem coordenação }\end{array}$ \\
\hline Cruzado & Único & Único & $\begin{array}{c}\text { Controle e objetivos rígidos } \\
\text { Controle disciplinar único }\end{array}$ & $\begin{array}{c}\text { Polarização de teores } \\
\text { disciplinares }\end{array}$ \\
\hline
\end{tabular}




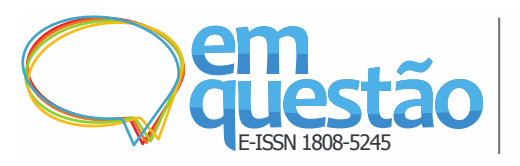

\begin{tabular}{|c|c|c|c|c|}
\hline Trans & Múltiplos & Múltiplos & $\begin{array}{c}\text { Axiomática geral consonante } \\
\text { ao nível dos objetivos } \\
\text { mútuos }\end{array}$ & $\begin{array}{c}\text { Coordenação orientada } \\
\text { Finalidade em comum } \\
\text { Surgimento de um } \\
\text { esquema epistemológico } \\
\text { (synepisetmologique) }\end{array}$ \\
\hline
\end{tabular}

Fonte: Baseado em Jantsch (1972, p. 106-107).

A mesma sistemática aplicada ao conceito de Interdisciplinaridade em Jantsch (1972) resulta a conformação apresentada pelo Quadro 3:

Quadro 3 - Apresentação sistemática das relações especificamente Interdisciplinares de Jantsch (1972), com explicitação de suas potencialidades Sistêmicas e relacionais

\begin{tabular}{|c|c|c|}
\hline \multicolumn{3}{|c|}{ Interdisciplinaridade } \\
\hline Forma de ocorrência & Tipo de sistema & Representação \\
\hline Característica: & Dois níveis & \\
\hline $\begin{array}{c}\text { Axiomática comum entre } \\
\text { disciplinas conexas }\end{array}$ & Axiomática mútua & \\
\hline Finalidade orientada & Objetivos múltiplos & \\
\hline Resultante: & Pontos de vista múltiplos & \\
\hline Convergência hierárquica & & \\
\hline $\begin{array}{l}\text { Coordenação definida por } \\
\text { uma axiomática comum }\end{array}$ & & \\
\hline
\end{tabular}

Fonte: Baseado em Jantsch (1972, p. 106-107).

Complementarmente às proposições de Jantsch (1972) e Heckhausen (1972), Japiassu (1976) discute o conceito de Interdisciplinaridade sob a luz da filosofia, sua obra foi escolhida pela recorrência com que foi encontrada nos artigos e textos nacionais sobre o tema, colaborando, a nosso ver, reflexivamente na discussão sobre o conceito. O autor, em uma de suas primeiras definições, refere o termo Disciplina como algo que significa o mesmo que "ciência", circunscrevendo o termo Disciplinaridade como algo que: 
[...] significa a exploração científica especializada de determinado domínio homogêneo de estudo, isto é, o conjunto sistemático e organizado de conhecimentos que apresentam características próprias nos planos do ensino, da formação, dos métodos e das matérias; esta exploração consiste em fazer surgir novos conhecimentos que se substituem aos antigos. (JAPIASSU, 1976, p. 72).

O autor passa, então, a discorrer sobre a possibilidade de definição do termo Interdisciplinaridade, reconhecendo-lhe uma condição de neologismo, ainda em processo de estabilização, propondo a abordagem de termos adjacentes (multi e pluridisciplinar) como forma de se compreender o processo interdisciplinar. Nesse sentido, Japiassu (1976) situa, também, o emprego das noções Pluri ou Multidisciplinar, quando:

[...] a solução de um problema só exige informações tomadas de empréstimo a duas ou mais especialidades ou setores do conhecimento, sem que as disciplinas levadas a contribuírem por aquela que as utiliza sejam modificadas ou enriquecidas. Em outros termos [...] consiste em estudar um objeto sob diferentes ângulos, mas sem que tenha necessariamente havido um acordo prévio sobre os métodos a seguir ou sobre os conceitos a serem utilizados. (JAPIASSU, 1976, p. 72, grifo nosso).

Japiassu (1976) refere-se ao trabalho de Jantsch (1972, p. 74, grifo do autor) apresentado sinteticamente nos Quadros 2 e 3 - como forma de ilustração dos graus de cooperação e coordenação de disciplinas numa situação de Interdisciplinaridade, relação estabelecida: “[...] pela intensidade das trocas entre os especialistas e pelo grau de integração real das disciplinas, no interior de um projeto específico de pesquisa.” .

A nosso ver, a contraposição feita por Japiassu (1976) entre os sentidos de Multidisciplinaridade, Pluridisciplinaridade e interdisciplinaridade impõe que se admita como uma diferenciação básica entre esses sentidos os tipos de relação neles existentes. De um lado as relações Multi e Pluridisciplinares que teriam como fator dominante uma situação de simples interação entre as disciplinas envolvidas no processo; do outro lado, uma relação estritamente Interdisciplinar, que seria conduzida por um fator de integração entre as disciplinas. Ou seja, no caso Pluri e Multidisciplinar o resultado é uma simples transferência de informações disciplinares (efeitos de uso localizado em cada disciplina), e, no caso Interdisciplinar o resultado é uma ação comunicativa interdisciplinar eficiente (efeitos de uso compartilhado entre as disciplinas).

No tocante ao "espaço" de ação interdisciplinar, Japiassu (1976, p. 74) defende que: 
Jamais esse espaço poderá ser constituído pela simples adição de todas as especialidades nem tampouco por uma síntese de ordem filosófica dos saberes especializados. O fundamento do espaço interdisciplinar deverá ser procurado na negação e na superação das fronteiras disciplinares.

Em razão de uma "realização" (finalização de um processo) como determinante para caracterização de um empreendimento Interdisciplinar, o autor advoga que o reconhecimento desse empreendimento só seria possível quando tal processo:

[...] conseguir incorporar os resultados de várias especialidades [...] tomar de empréstimo a outras disciplinas certos instrumentos e técnicas metodológicos, fazendo uso dos esquemas conceituais e das análises que se encontram nos diversos ramos do saber, a fim de fazê-los integrarem e convergirem depois de terem sido comparados e julgados. (JAPIASSU, 1976, p. 75, grifo do autor).

Ao situar o termo Transdisciplinaridade, criação creditada à Piaget (1972), observa que o termo está circunscrito a uma etapa posterior ao das relações interdisciplinares. Essa etapa Transdisciplinar, segundo Japiassu (1976), estaria em um patamar superior de relacionamento, e não se configuraria possível sem a transformação da realidade, então, presente, ou seja, poderia ser visto como um projeto "ideal”, mas não "aplicável” nas condições de uma ciência ainda em debate sobre a dinâmica interacional de suas várias disciplinas.

Por último, fazendo uso da divisão proposta por Heckhausen (1972) - apresentado sinteticamente no Quadro 1, Japiassu (1976) reduz tais divisões à dois tipos: (1) Interdisciplinaridade Linear ou Cruzada, uma pluridisciplinaridade mais sofisticada em que há trocas, mas não reciprocidade, com um grau quase nulo de cooperação metodológica, com "disciplinas auxiliares" ao processo funcionando como componentes dependentes ou subordinadas ao mesmo; e, (2) Interdisciplinaridade Estrutural, em que o diálogo entre disciplinas é igualitário, sem supremacia de uma em detrimento de outra(s), promovendo enriquecimento mútuo, sendo disponibilizados, comunitariamente, os axiomas, conceitos e métodos, o que promove "fecundação" recíproca (resultando, geralmente, uma nova disciplina).

Nessas condições, nossas considerações sobre as posições assumidas pelo autor em relação às proposições de Jantsch (1972) são as mesmas no que concerne às proposições de Heckhausen (1972), considerações pelas quais lançamos mão da Teoria da Ação 
Comunicativa como proposta de integração entre setores nem sempre, eficientemente, intercambiáveis em nível social.

\section{Conceitos habermasianos da Teoria da Ação Comunicativa}

Compreendemos o conceito de Esfera Pública como o de um espaço intermediário entre mundos privados e públicos, observando, nessa questão privada, a consideração de aspectos impactantes na vida do Sujeito, que age de forma reflexiva ao nível social e ao nível doméstico. O conceito de Esfera Pública é, pois, definido por Habermas (1984, p. 42) como:

[...] a esfera das pessoas privadas reunidas em um público; elas reivindicam esta esfera pública regularmente pela autoridade, mas diretamente contra a própria autoridade, a fim de discutir com ela as leis gerais da troca na esfera fundamentalmente privada, mas publicamente relevante, as leis de intercâmbio de mercadorias e do trabalho social.

Nesse sentido, o conceito, se considerarmos a premissa por nós advogada, pode ser considerado como circunscrito ao espaço de intermediação de nosso recorte, o que Habermas denomina como Mundo Social (parte composta por sua vez de temas como os de Sistemas de autoridade) - conceituando nesse prisma sistêmico as instituições científicas tanto de pesquisa quanto de fomento à pesquisa - em contraposição a um Mundo da Vida.

A concepção de Mundo da Vida em Habermas é definida por Aragão (1992, p. 44) como sendo: “[...] o pano-de-fundo que permite aos sujeitos capazes de fala e ação se entenderem mutuamente sobre algo no mundo, seja este mundo o mundo exterior natural, o mundo exterior social, ou o mundo interior subjetivo.", incluindo, dessa maneira, tanto o cidadão-indivíduo quanto sujeito da ordem doméstica na ordem de uma potencial participação enquanto Sujeito de ação influente na ordem social.

Além do conceito de Esfera Pública, outros conceitos foram por nós considerados como a ele relacionados, tais como: o da Racionalidade; o da Ação Comunicativa entre os componentes sociais envolvidos no processo comunicativo; e o de Pretensão de Validez dos argumentos expressos nos discursos produzidos por esses elementos, todos eles concernentes ao ato comunicativo-discursivo em pauta (de ordem interdisciplinar).

Uma primeira distinção entre os aspectos conotativos atribuídos por Habermas (1987, 
p. 27, tradução nossa) a respeito do conceito de Racionalidade dá-se pela contraposição entre o sentido de uma Racionalidade Cognitivo-Instrumental, entendida como: "[...] uma autoafirmação com êxito no mundo objetivo possibilitada pela capacidade de manipular informadamente e de adaptar-se inteligentemente às condições de um entorno contingente."7; e, Racionalidade Comunicativa, como aquela que remonta:

[...] a uma experiência central da capacidade de unir sem coações e de gerar consenso que tem uma fala argumentativa em que diversos participantes superam a subjetividade inicial de seus respectivos pontos de vista e, obrigados a uma comunidade de convicções racionalmente motivada, asseguram ao mesmo tempo a unidade do mundo objetivo e da intersubjetividade do contexto em que se desenvolvem suas vidas. ${ }^{8}$ (HABERMAS, 1987, p. 27, tradução nossa).

Entendemos que o diferencial estabelecido entre ambos os conceitos, no que tange à realização de ações "racionais", reside nos objetivos pelos quais dirigem essa ação no meio social: um processo comunicativo racional que mantém seu lastro com o interesse não exatamente de concordância pelo conteúdo que argumentam, mas sim, pelo "consenso" racionalmente fundamentado em torno de sua realização, ou não. E, em contrapartida, um processo racional cognitivo-instrumental - baseado em um interesse "auto-afirmativo" como aquele que utiliza como base de seu exercício outras justificativas que não sejam, exatamente, fundamentadas num mundo objetivo coletivamente compartilhado (mundo social) $)^{9}$.

A nosso ver, torna-se necessário abordar a questão argumentativa em ambos os processos acima definidos, uma vez que é por meio da argumentação - expressa em enunciados - que tais processos finalizam seus objetivos.

Habermas (1987, p. 37, tradução nossa) chama de "Argumentação" o tipo de "fala": “[...] em que os participantes tematizam as pretensões de validez que se hão tornado duvidosas e tratam de desempenhá-las ou de recusá-las por meio de argumentos." ${ }^{, 10}$, ou seja, são valores favoráveis ou desfavoráveis incluídos nas "enunciações", que defendem ou acusam a "verdade", ou a "pretensão de verdade" (como válidos ou inválidos) - Pretensões de Validez -, do conteúdo proposicional exposto pelos debatedores.

Ao estender o critério de Racional ao âmbito dos Sujeitos da ação, Habermas (1987, p. 37, tradução nossa) distingue tais Sujeitos, também, pela consonância destes em posturas "cognitivo instrumentais", caracterizando-os, por uma primeira ordem, como uma 
classe de pessoas que: “[...] expressa opiniões fundadas e atua com eficiência [...]"11, asseverando, no entanto, que tal base racional: “[...] permanece contingente se não vai, por sua vez, conectada a capacidade de aprender dos desacertos, da refutação de hipóteses e do fracasso das intervenções no mundo."12.

Quando o autor avalia tais Sujeitos na condição de realizadores, em ordens "práticomorais" (em vertentes comunicativo-racionais), classifica-os como sujeitos racionais, pela condição de que orientam suas decisões como:

[...] aquele que em um conflito normativo atua com lucidez, quer dizer, não se deixando levar por suas paixões, nem entregando-se aos seus interesses imediatos, mas esforçando-se por julgar imparcialmente a questão de um ponto de vista moral e por resolvê-la consensualmente. ${ }^{13}$ (HABERMAS, 1987, p. 38, tradução nossa).

O conceito de Ação Comunicativa é definido por Habermas (1987, p. 124, tradução nossa) como:

[...] a interação de ao menos dois sujeitos capazes de linguagem ou de ação que (seja por meios verbais ou com meios extra-verbais) se envolvem numa relação interpessoal. Os atores buscam entender-se sobre uma situação de ação para poder, assim, coordenar, de comum acordo, seus planos de ação e, com eles, suas ações. ${ }^{14}$

A Linguagem, como fator preponderante de manifestação dos conteúdos discursivos, é entendida por Habermas (1987, p. 138, tradução nossa), no âmbito da Ação Comunicativa, como um:

[...] meio de entendimento sem mais abreviaturas, em que falantes e ouvintes se referem, desde o horizonte pré-interpretado que seu mundo da vida representa, simultaneamente, a algo no mundo objetivo, no mundo social e no mundo subjetivo, para negociar definições da situação que podem ser compartilhadas por todos. ${ }^{15}$

A Linguagem seria, pois, em nossa acepção - e a partir dessa proposição do autor um mecanismo pelo qual as interações comunicativas se efetivam, nos diversos tipos de ação (cada qual ostentando características específicas do espaço em que circulam) apresentados por Habermas (1987), nas seguintes condições e circunstâncias: Teleológico-estratégica, como maneira de influir decisivamente para o êxito do grupo discursivo; Normativa, como forma de manutenção/transmissão de "valores culturais" comunitariamente compartilhados; Dramatúrgica, no interesse de imprimir um efeito de ordem "estética" ou "estilística" que se sobreponha ao conteúdo "ilocutório". 


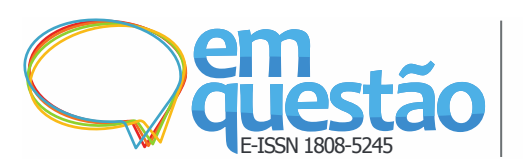

No tocante ao processo de Ação Comunicativa, e ao processo argumentativo exigido aos Sujeitos, também referem-se questões de "valor" à validade das pretensões defendidas Pretensões de Validez -, e a um Sujeito em relação ao outro. Ou seja, lançando mão do princípio de racionalidade de suas ações, são avaliadas as premissas argumentadas, e são objetivadas diretivas a partir do entendimento mútuo. Habermas (1987) reconhece a contemplação de três Pretensões de Validez: de verdade do enunciado, pelo valor de correspondência entre o enunciado e o mundo objetivo; de legitimidade discursiva, pelo valor de atenção normativa entre contexto e enunciado; e, de "sinceridade" do enunciado, pelo que se avalia concordância entre discurso e pensamento.

Tais categorias de Pretensões de Validez estão intimamente relacionadas, segundo Habermas (1987, p. 114-144, tradução nossa), com três conceitos adjacentes: de mundo objetivo, definido como: “[...] conjunto de todas as entidades sobre as quais são possíveis enunciados verdadeiros [...]"16; de mundo social, como: “[...] conjunto de todas as relações interpessoais legitimamente reguladas [...]"17, e, de mundo subjetivo, como: “[...] totalidade das vivências do falante, àquelas que este tem um acesso privilegiado [...]"18.

\section{Interdisciplinaridade como espaço de ação comunicativa}

A contraposição dialética do processo hermenêutico administrado na seção anterior resulta nas considerações de que os autores, filiados aos campos de Filosofia, por Japiassu (1976), Filosofia da Ciência, por Habermas (1987), e uma Sociologia da Ciência com enfoque na questão de Inovação - sobretudo pelas abordagens de Jantsch (1972) e Alvarenga et al. (2011), estes últimos autores presentes em obra publicada em parceria com a Coordenação de Aperfeiçoamento de Pessoal de Nível Superior (CAPES), advogam posicionamentos semelhantes em dois níveis:

a) de teor reflexivo, no que tange aos princípios de produção de conhecimento (JAPIASSU, 1976; HABERMAS, 1987), divergindo apenas na consideração do tema Interdisciplinaridade no primeiro, e, em contrapartida, pela consideração do processo comunicativo como ação social emancipatória, no segundo;

b) e, de teor aplicado, no que tange ao conceito de relações interdisciplinares (JANTSCH, 1972; HENKHAUSEN, 1972; ALVARENGA et al., 2011), com o primeiro e o último convergindo na questão da inovação como fator de 


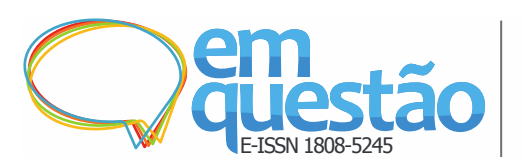

\section{A interdisciplinaridade como instrumento de ação comunicativa ${ }^{1}$}

Marco Donizete Paulino da Silva e Luciana de Souza Gracioso

enfoque, e o segundo divergindo apenas no tocante à abordagem do tema Interdisciplinaridade como componente de interesse em campos de aplicação de diversas modalidades (ensino, pesquisa, científico e profissional).

No desenvolvimento de nossa análise dialética compreendemos que a Teoria da Ação Comunicativa apresenta graus potenciais de asserção enquanto argumento de estabilização de um processo democrático eficiente - ainda que idealista, uma vez que nossa realidade conjuga vários obstáculos a essa proposição. Um dos pontos relevantes ao exercício democrático reside na consideração do processo de Ação Comunicativa eficiente em detrimento de uma eficiente Ação Comunicativa de interesse instrumental estratégico ${ }^{19}$.

O conceito de Ação Social, como um objetivo a ser observado nas diversas formas de acontecimento, é definida por Habermas (1987) a partir dessas várias óticas: no plano da Ação Teleológica, como coordenação de interesses mútuos e utilitários entre os participantes da interação; no plano da Ação Normativa, como forma de manutenção da integração comunitária pela manutenção/reprodução de tradições e normas; no plano da Ação Dramatúrgica, pela divisão convencional entre um "ator" e uma "audiência"; e, no plano da Ação Comunicativa, pela vinculação entre o entendimento mútuo de sentido no "processo cooperativo de interpretação".

O conceito de Ação Comunicativa, em decorrência de sua exigência de efetiva realização do ato comunicativo - consenso interpretativo -, foi considerado como "suporte" de uma condição ao mesmo tempo resultante e produtora de uma "nova" racionalidade, tida como essencial para o estabelecimento de uma ordem social - em nível global, nacional ou regional - que atenda às necessidades impostas pelas realidades ambientais e comunitárias refletidas nas ordens sociais, científicas e político-administrativas.

Essa nossa defesa se situa na percepção inicial de que o pensamento do sujeito cognoscente (Subjetividade Onomasiológica Humana) e o Sistema Epistemológico Científico são entendidos como dois universos de conhecimento (Mundo Subjetivo, Mundo Social) pautados pela solução-satisfação de uma resposta a um problema mútuo pertinente a um Mundo da Vida que, caracteristicamente complexo, necessita de uma ferramenta/tecnologia capaz de estabelecer conexões pertinentes e eficientes para ambos (ferramenta/tecnologia que se concretiza no conceito de Interdisciplinaridade, do qual o uso salienta a qualidade de intermediação crítica tanto potencial quanto necessária). 


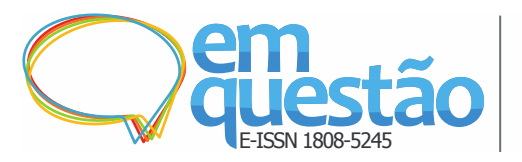

Dessa feita, entendemos que as redes tanto do universo onomasiológico humano (subjetividade) quanto do universo epistemológico científico (sistemas) lançam mão de componentes que exigem interação de nível "público", para se fazerem perceptíveis tanto em nível exploratório quanto produtivo. Ou seja, as “divisões” disciplinares (ou especialistas) contidas em ambos os sistemas procuram "conscientizar" as conexões necessárias (interdisciplinares) para manifestarem respostas adequadas, lógicas ou satisfatórias em relação ao mundo que ambos compartilham: um universo epistemológico em comum (o Mundo da Vida, considerado aqui uma Epistemologia Geral, resultante da interação social em diversos níveis).

A nosso ver, o conceito de Esfera Pública dilatou - pela dinamização dos processos comunicacionais proporcionada pelas Tecnologias de Informação e Comunicação (TICs) - sua capacidade de fluxos discursivos tanto de documentos formais (pertencentes ao mundo dos Sistemas: relatórios, orientações, estatutos, etc.) que orientam aspectos definidores da pesquisa Interdisciplinar quanto de produtos formais (que tentam descrever, de maneira holística, uma realidade circundante impressa em: teses, dissertações, artigos, etc.) dos processos de investigação científica, circunscrevendo o cidadão/indivíduo/sujeito (identidade societária/identidade privada/identidade subjetiva) e o Mundo da Vida (todo) em sua dinâmica comunicativa.

Tal ampliação, ao mesmo tempo em que possibilitou o acesso democrático às informações contidas nessas divisões necessariamente interdependes, também exigiram que se ampliassem as formas de "capacitação" comunicativa dos sujeitos como agentes sociais (em âmbitos domésticos e institucionais) em todos os níveis de acesso aos fatos, exigindo-lhes, consequentemente, maior participação nos processos decisórios acerca desses fatos a partir de sua inserção efetiva na Esfera Pública por meio de interfaces que possibilitassem compreensão, também efetiva, dos processos decisórios.

Essa exigência se dá porque as condições para construção de uma nova Epistemologia Geral necessitam da "renovação" do processo de comunicação entre essas divisões estruturais de processos discursivos em níveis subjetivos (indivíduo/cidadão/sujeito) e burocráticos (instituição), uma vez que os rumos de um desenvolvimento científico e tecnológico devam ser consciente e criticamente orientados não só pelo crivo político governamental, mas também por uma coletividade participante - o que Bunge (1980) denomina como estilo Sistêmico de gerenciamento das políticas de desenvolvimento científico. 


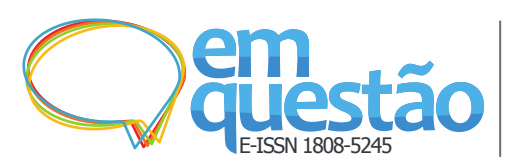

\section{A interdisciplinaridade como instrumento de ação comunicativa ${ }^{1}$}

Marco Donizete Paulino da Silva e Luciana de Souza Gracioso

Na acepção de Bunge (1980) o caráter de gerenciamento Sistêmico é traçado: “[...] com a participação dos pesquisadores científicos e levando em consideração tanto a necessidade de desenvolvimento de todas as ciências como as necessidades da tecnologia, assim como a posição central da ciência na cultura contemporânea.” (BUNGE, 1980, p. 232).

Por essa concepção, segundo o autor, a ciência é colocada em pé de igualdade com os outros setores da sociedade, sendo tal estilo de planejamento caracterizado pelos seguintes elementos, nas seguintes condições: Integralidade, conferindo atenção a todas as ciências; Modernidade, priorizando a atualidade da pesquisa; Moderação, consciência da necessidade de flexibilização pertinente; Agilidade, administração dinâmica tanto da estrutura quanto dos recursos; Realismo, consideração das circunstâncias reais da pesquisa; e, Participação, estímulo à inclusão dos cientistas no processo de planejamento, assim como, da cooperação dos agentes do Estado.

Ainda que esse autor não saliente a participação do cidadão/sujeito no processo decisório - indicando o "especialista" como contrapeso ao poder estatal -, interpretamos interesse de consenso social na consideração da Ciência como componente central de uma determinada "cultura" (sociedade). Além disso, advogamos a menção dessa proposta pela percepção de que é a que mais se aproximou da proposta de Esfera Pública como espaço social de intermediação e, portanto, de interesse comunicativo eficiente.

Ao abordar a questão da Linguagem - forma de expressão dos conteúdos proposicionais em debate no processo comunicativo, Habermas (1987) inclui, enquanto objetos passíveis de avaliação, três categorias linguísticas: (1) Simbólicas, comportando os atos de fala (enunciados), as atividades teleológicas, etc.; (2) Sedimentares, que têm em seu arcabouço os textos, as teorias, as tradições, etc.; e, (3) Sistêmico-estruturais, que se concretiza nas formas institucionais ou organizacionais de arranjo social, ou pessoal (estrutura psicológica, por exemplo).

Entendemos que, ainda que o conceito de Compreensão esteja intimamente relacionado ao fator metodológico, alguns apontamentos de Habermas (1987) em referência à ideia de Compreensão são pertinentes de abordagem de apreensão dos enunciados pelos sujeitos em ação comunicacional. Nesse sentido, uma questão que nos parece coerente observar é que o processo de compreensão se dá somente quando o sujeito tem: “[...] acesso a ele, participando, ao menos virtualmente, nas comunicações de seus membros e, portanto, convertendo-se a si mesmo em um membro, ao menos, potencial." ${ }^{20}$ (HABERMAS, 


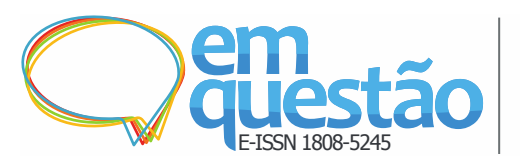

1987 p. 160, tradução nossa), o que significa dizer que, mesmo que não faça parte, efetiva e factualmente, do universo investigado (participação virtual), exige-se que o sujeito entenda seus processos de enunciação e sua base histórico-sociológica (participação potencial), ambos situados em um tempo histórico e social.

O que nos permite entender que, no que concerne à exigência de compreensão de determinada enunciação, exige-se tanto um reconhecimento do contexto de emissão quanto dos objetivos pré-estabelecidos pelos sujeitos que a enunciaram, mas também das "interfaces" que possibilitariam eficiência comunicacional. O que nos permitiria, enquanto avaliadores das Pretensões de Validez dos sujeitos de determinada ação enunciativa, identificar: os tipos de ação que determinada enunciação demonstraria efetivar, ou seja, se a enunciação corporificaria objetivos de fundo teleológico-estratégico, normativo, dramatúrgico ou comunicativo; e, a possibilidade de tal interface necessitar de um mecanismo mediacional que teria na Interdisciplinaridade, por seu caráter não compartimental, um elemento de integração capaz de verificar a validade de tais ordens de formulação.

\section{Considerações finais}

Nas considerações finais, buscamos convergência entre questões de ordem prático-morais, e nossas proposições, advogando que tanto a qualidade "racional" de sujeitos e processos quanto dos teores de "Pretensão de Validez" - expostos nas enunciações/argumentações desses sujeitos em disputa pela "verdade" de suas articulações discursivas - concernentes a tomadas de decisão eficientes do ponto de vista holístico são, a nosso ver, elementos essenciais ao processo de reconstrução uma epistemológica geral mais responsável, do ponto de vista dos impactos decisórios humanos. Nesse sentido, o processo comunicativo que as instituições/sistemas (Campos Científicos e Organizações de Fomento da Ciência, por exemplo) utilizam cotidianamente para estabelecerem políticas de manutenção, estimulação ou não estimulação das pesquisas são, potencialmente, vitais para o planejamento e exercício de uma Ciência menos enclausurada e mais acessível ao leigo.

A nosso ver, tanto como área-território quanto forma relacional de pesquisa, o fenômeno Interdisciplinar é uma questão de uso racional - na ordem científica contemporânea (num âmbito maior, do mundo) - do conceito Interdisciplinaridade em argumentações expressas na ordem das enunciações de sujeitos do campo científico e na ordem de 


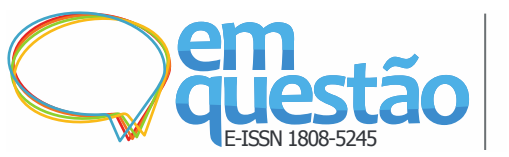

componentes dos sistemas de fomento da ciência, uma vez que são ordens, visceralmente, entrelaçadas a realidades contemporâneas que exigem ações comunicativas de fundo racional, ou seja, os processos informacionais dos vários núcleos sociais (entre sistemas especialistas e indivíduos leigos) é uma necessidade intransferível e inadiável.

Por essa via, mesmo que tenhamos proposto a discussão de um processo de articulação discursiva entre textos de ordem teórica, entendemos que a elevação dessa discussão em um nível mais amplificado deverá multiplicar-se em outros trabalhos de pesquisa - talvez também de ordem aplicada - que aprofundem nosso questionamento.

Nesse sentido, tais investigações poderiam observar o funcionamento das estruturas sistêmicas que permitem (ou estimulam) a frágil formação crítica: dos pesquisadores, formados para atuarem por meio da produção prolífica e progressiva de intervenções técnicocientíficas no mundo social; e, do cidadão comum que, em relação aos temas científicos, se vê inserido numa ordem epistemológica hostil a sua ação decisória relevante, sendo privado de uma comunicação eficiente do conteúdo de caráter científico que lhe proporcionaria uma melhor atuação.

Nesses dois sujeitos (pesquisador e cidadão) a conscientização sobre os impactos decisórios da ciência no ambiente social global, e a consequente cobrança de uma participação decisória impactante de ambos nesses âmbitos, é uma realidade que, a nosso ver, não pode ser ignorada, já que a qualidade do processo comunicativo eficiente - expresso em uma arena pública de debates - é proporcional à qualidade intersubjetiva crítica tanto do pesquisador quanto do cidadão em relação ao Mundo da Vida e dos Sistemas.

Dessa maneira, o aspecto de "divulgação científica" - distribuição de informação científica de forma menos hermética ao leigo - parece ser um dos aspectos a ser explorado no tocante a estratégias de estimulação interdisciplinar, pois, uma vez que a participação efetiva do indivíduo na Esfera Pública em questões relativas a temas da Ciência exigem que tal cidadão, tanto para argumentar favoravelmente, ou não, em relação a proposições especialistas do campo científico, compreenda os aspectos básicos em pauta e, as consequências dessas decisões em curto, médio e longo prazo, ou em nível micro ou macro, social ou sócio-ambiental. 


\section{Referências}

ALVARENGA, Augusta Thereza de et al. Histórico, fundamentos filosóficos e teóricometodológicos da interdisciplinaridade. In: PHILIPPI JUNIOR, Arlindo; SILVA NETO, Antonio J. (Ed.). Interdisciplinaridade em Ciência, Tecnologia \& Inovação. Barueri: Manole, 2011. p. 3-68.

APOSTEL, Léo et al. Interdisciplinarity: problems of teaching and research in universities. Paris: Centre for Educational Research and Innovation, 1972.

ARAGÃO, Lucia Maria de Carvalho. Razão comunicativa e teoria social crítica em Jürgen Habermas. Rio de Janeiro: Tempo Brasileiro, 1992.

BLANCHÉ, Robert. A epistemologia. Lisboa: Editorial Presença, 1978.

BUNGE, Mario. Epistemologia: curso de atualização. São Paulo: Editora Universidade de São Paulo, 1980.

GIL, Antonio Carlos. Métodos e técnicas de pesquisa social. 2. ed. São Paulo: Editora Atlas A.S., 1989.

GONZÁLEZ DE GÓMEZ, Maria Nélida. A universidade e a "sociedade da informação". Revista Digital de Biblioteconomia e Ciência da Informação, Campinas, v. 9, n. 1, p. 225242, jul./dez. 2011.

HABERMAS, Jürgen. Mudança estrutural da esfera pública. Rio de Janeiro: Tempo Brasileiro, 1984.

HABERMAS, Jürgen. Teoría de la acción comunicativa, I. Madri: Taurus Humanidades, 1987.

HECKHAUSEN, Heinz. Discipline and interdisciplinarity. In: APOSTEL, Léo et al. Interdisciplinarity: problems of teaching and research in universities. Paris: Centre for Educational Research and Innovation, 1972. p. 83-89.

JANTSCH, Erich. Towards interdisciplinarity and transdisciplinarity in education and innovation. In: APOSTEL, Léo et al. Interdisciplinarity: problems of teaching and research in universities. Paris: Centre for Educational Research and Innovation, 1972. p. 97-121.

JAPIASSU, Hilton. Interdisciplinaridade e a patologia do saber. Rio de Janeiro: Imago Editora, 1976.

JAPIASSU, Hilton. Introdução ao pensamento epistemológico. Rio de Janeiro: Francisco Alves, 1992.

MINAYO, Maria Cecília de Souza. Hermenêutica-dialética como caminho do pensamento social. In: MINAYO, Maria Cecília de Souza; DESLANDES, Suely Ferreira. (Org.). Caminhos do pensamento: epistemologia e método. Rio de Janeiro: Editora Fio Cruz, 2002. p. 83-107. 
PIAGET, Jean. The epistemology of interdisciplinary relationship. In: APOSTEL, Léo et al. Interdisciplinarity: problems of teaching and research in universities. Paris: Centre for Educational Research and Innovation, 1972. p. 127-140.

RASLAN FILHO, Gilson Soares. Conjunções e disjunções entre comunicação e poética: alguns apontamentos. Intexto, Porto Alegre, n. 27, p. 173-182, dez. 2012.

SANTOS, Boaventura de Souza. Pela mão de Alice: o social e o político na pósmodernidade. São Paulo: Cortez, 2001.

\title{
Interdisciplinarity as an instrument of communicative action
}

\begin{abstract}
This paper is based on the perception of the need for a holistic consideration of the epistemological elements involved in the construction of knowledge in contemporary time, having as key elements, both the requirement of a citizen's awareness of the individual and the use of an instrument that enhances this awareness, to recognize the utopian character of this project. The concept of interdisciplinarity (and its multiple meanings) was understood as a recurrent application resource in the development and expansion of human and scientific knowledge. The articulation of these premises propose the consideration of the term Interdisciplinarity as an instrument-technology of communicative action, capable of mediating the world of life and the socio-institutional systems, promoting the encounter (or resulting from the encounter) of intersubjectivities of subjects acting in those two spaces. In order to verify the pertinence of this proposition, the hermeneutic-dialectical analysis was applied on national and international texts that approach the concept of Interdisciplinarity from the perspective of several theorists of the Philosophy and Sociology field. The arguments about this theme were based on the following basic concepts in the following affiliations: Communicative Action, Rationality, and Pretensions of Validity, by Jürgen Habermas; and, of Interdisciplinarity, in Leo Apostel et al. - with considerations of Japiassu and Alvarenga et al. We concluded that the environment of the public sphere is potentially a space of interdisciplinary construction of knowledge and that its conscientious nature could benefit the wider promotion of Interdisciplinarity in differentiated spaces.
\end{abstract}

Keywords: Interdisciplinarity. Theory of Communicative Action. Hermeneutic-dialectical method. Subject of Communicative Action. World of Life.

Recebido: 06/09/2017

Aceito: $27 / 10 / 2017$

${ }^{1} \mathrm{O}$ artigo origina-se de Tese de Doutorado, apresentando modulações em relação ao texto original. 
2 Parece-nos passível a articulação desse tema em Pierre Bourdieu, sobretudo em relação aos conceitos de Espaço Social e Agente Social - similares aos selecionados em Habermas. No entanto, dada a complexidade dessa proposta, tal possibilidade não será explorada nesse trabalho.

3 "[...] lead to differentianting at least six types of intedisciplinarity. At the same time, this typology points to various urges towards interdisciplinarity, in the research field or in the field of vocational practice and the complex interaction between the two." (p. 86).

4 " [...] is essentially a static principle which becomes meaningless if considered in the framework of a purposive system." (JANTSCH, 1872, p. 103).

5 "It is no wonder that in a time when science is becoming increasingly understood as basis for, or even integral aspect of, creative human action, the emphasis is shifting to more orless interdisciplinary approaches." (JANTSCH, 1972, p. 103).

6 "A common axiomatics for a group of related disciplines is define at the next higher herarchical level or sublevel, thereby introducing a sense of purpose; teleological interdisciplinarity acts between the empirical and pragmatic levels, normative interdisciplinarity between the pragmatic and normative levels, purposive interdisciplinarity between the normative and purposive levels." (JANTSCH, 1972, p. 106).

7 “[...] una autoafirmación com exito en el mundo objetivo posibilitada por la capacidad de manipular informadamente y de adaptarse inteligentemente a las condiciones de un entorno contingente." (HABERMAS, 1987 , p. 27).

8 " [...] a la experiencia central de la capacidad de aunar sin coacciones y de generar consenso que tiene una habla argumentativa en que diversos participantes superan la subjetividad inicial de sus respectivos puntos de vista y merced a una comunidad de convicciones racionalmente motivada se aseguran a la vez de la unidad del mundo objetivo y de la intersubjetividad del contexto en que se desarollan sus vidas." (HABERMAS, 1987, p. 27).

9 O mundo social faz parte, a nosso ver, do Mundo da Vida por esse definir-se como "totalidade".

10 "[...] en que los participantes tematizan las pretensiones de validez que se han vuelto dudosas y tratan de desempeñarlas o de recursarlas por medio de argumentos.” (HABERMAS, 1987, p. 37).

11 “[...] expressa opiniones fundadas y actúa con eficiencia [...]” (HABERMAS, 1987, p. 37).

12 "[...] permanece contingente si no va a su vez conectada a la capacidad de aprender de los desaciertos, de la refutación de hipótesis y del fracasso de las intervenciones en el mundo.” (HABERMAS, 1987, p. 37).

13 " [...] aquel que en un conflicto normativo actúa con lucidez, es decir, no dejándose llevar por sus pasiones ni entregándose a sus intereses inmediatos, sino esforzándose por juzgar inparcialmente la cuestión desde un punto de vista moral y por resolverla consesualmente." (HABERMAS, 1987, p. 38).

14 "[...] la interacción de a lo menos dos sujetos capaces de lenguage u de acción que (ya sea con medios verbales o con medios extra-verbales) entablan una relación interpessonal. Los atores buscan enterederse sobre una situación de acción para poder así coordinar de comun acuerdo sus planes de acción y con ello sus acciones." (HABERMAS, 1987, p. 124).

15 "[...] medio de entendimiento sin más abreviaturas, en que hablantes y oyentes ser refierem, desde el horizonte preinterpretado que su mundo de la vida representa, simultáneamente a algo en el mundo objetivo, en el mundo social y en el mundo subjetivo, para negociar definiciones de la situación que puedan ser compartidas por todos." (HABERMAS, 1987, p. 138).

16 "[...] conjunto de todas las entidades sobre las que son posibles enunciados verdaderos [...]" (HABERMAS, 1987, p. 144).

17 “[...] conjunto de todas las relaciones interpesonales legítimamente reguladas [...]” (HABERMAS, 1987, p. 144).

18 “[...] totalidad de las vivencias del hablante, a las que éste tiene un acceso privilegiado [...]" (HABERMAS, 1987, p. 144).

19 Este tipo de Ação é categorizado por Habermas (1987) como sendo do tipo Teleológico, que exige uma decisão entre possibilidades de ações alternativas, tendo como orientação a realização de um objetivo, conforme valores e interpretação dos agentes que a propõe - podendo derivar-se numa "forma" Estratégica quando precede a um "cálculo" (inerente a uma expectativa de êxito), buscando atingir o "agente" opositor no processo comunicativo.

20 "[...] acceso a él participando, al menos virtualmente, en las comunicaciones de sus miembros y por tanto conviertiéndose a sí mismo en un miembro por lo menos potencial.” (HABERMAS, 1987, p. 160). 